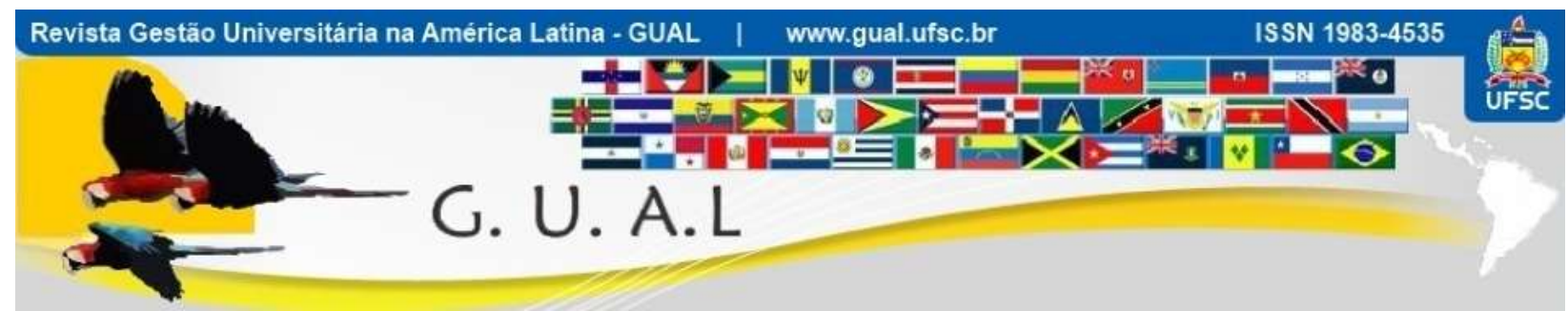

DOI: https://doi.org/10.5007/1983-4535.2021.e75461

\title{
CULTURA ORGANIZACIONAL DE UMA UNIVERSIDADE BRASILEIRA: UMA ANÁLISE DOS VALORES E PRÁTICAS ORGANIZACIONAIS NA PERCEPÇÃO DOS DOCENTES
}

\section{ORGANIZATIONAL CULTURE OF A BRAZILIAN UNIVERSITY: AN ANALYSIS OF ORGANIZATIONAL VALUES AND PRACTICES IN THE PERCEPTION OF TEACHERS}

Maria Julia Pegoraro Gai, Mestre https://orcid.org/0000-0002-8481-1112 mariajuliagai@hotmail.com

Universidade Federal de Santa Catarina | Programa de Pós-Graduação em Psicologia Florianópolis | Santa Catarina | Brasil

Vânia Medianeira Flores Costa, Doutora https://orcid.org/0000-0002-6099-820X vania.costa@ufsm.br

Universidade Federal de Santa Maria | Departamento de Ciências Administrativas Santa Maria | Rio Grande do Sul | Brasil

Luis Felipe Dias Lopes, Doutor https://orcid.org/0000-0002-2438-0226 1flopes67@yahoo.com.br

Universidade Federal de Santa Maria | Departamento de Ciências Administrativas Santa Maria | Rio Grande do Sul | Brasil

Natália Funghetto Dapieve, Graduada https://orcid.org/0000-0002-8593-3605 nataliadapieve10@gmail.com Universidade Federal de Santa Maria | Programa de Pós-Graduação em Administração Santa Maria | Rio Grande do Sul | Brasil

Mauren Pimentel Lima, Mestre https://orcid.org/0000-0002-0215-1190 maurenplima@gmail.com

Recebido em 05/julho/2020

Universidade Federal de Santa Maria | Programa de Pós-Graduação em Enfermagem Aprovado em 03/fevereiro/2021

Publicado em 01/maio/2021 Santa Maria | Rio Grande do Sul | Brasil

Sistema de Avaliação: Double Blind Review

O presente trabalho foi realizado com apoio da Coordenação de Aperfeiçoamento de Pessoal de Nível Superior - Brasil (CAPES) - Código de Financiamento 001 


\title{
RESUMO
}

A cultura da organização exerce reflexos em diversos âmbitos do trabalho e no comportamento organizacional. Por isso, este estudo teve como objetivo identificar a cultura organizacional de uma universidade brasileira. Trata-se de um estudo de caso de abordagem mista. Na etapa quantitativa utilizou-se o Instrumento Brasileiro para Avaliação da Cultura Organizacional, em que se obteve dados de 200 respondentes, submetidos a análises de estatística descritiva e padronização das escalas. A etapa qualitativa deu-se por meio de entrevistas com 8 docentes, que passaram por análise de conteúdo. Os resultados indicam uma percepção positiva a respeito cultura organizacional da universidade, já que todos os fatores foram classificados de moderado a alto. Esses dados foram corroborados pelas análises qualitativas, pelas quais é possível indicar a elaboração de estratégias para modificação gradual da cultura organizacional visando proporcionar um local de trabalho com uma cultura que favoreça ainda mais o desenvolvimento das atividades dos docentes.

Palavras-chave: Cultura Organizacional. Universidades. Docentes.

\begin{abstract}
The organization's culture affects different areas of work and organizational behavior. Therefore, this study aimed to identify the organizational culture of a Brazilian university. This is a mixed-approach case study. In the quantitative stage, the Brazilian Instrument for Assessment of Organizational Culture was used, in which data from 200 respondents were obtained, submitted to descriptive statistical analysis and standardization of scales. The qualitative stage took place through interviews with 8 professors, who underwent content analysis. The results indicate a positive perception about the university's organizational culture, as all factors were classified from moderate to high. These data were corroborated by qualitative analyses, through which it is possible to indicate the development of strategies for the gradual modification of the organizational culture in order to provide a workplace with a culture that further favors the development of the activities of the professors.
\end{abstract}

Keywords: Organizational Culture. Universities. Professors. 


\section{CULTURA ORGANIZACIONAL DE UMA UNIVERSIDADE BRASILEIRA: UMA ANÁLISE DOS \\ VALORES E PRÁTICAS ORGANIZACIONAIS NA PERCEPÇÃO DOS DOCENTES \\ DOI: https://doi.org/10.5007/1983-4535.2021.e75461}

\section{INTRODUÇÃO}

O interesse pela compreensão dos aspectos culturais nas organizações começou a se manifestar nas últimas quatro décadas, quando se identificou a interferência desse fator nos recursos das organizações, tanto humanos como materiais. A cultura passou a ser visualizada como uma variável estratégica para as organizações e não mais um elemento secundário ou despercebido. Com o termo "cultura organizacional", os teóricos buscaram dar ênfase à relevância das questões simbólicas no meio organizacional, discutindo sobre o efeito dos valores, crenças e símbolos no comportamento dos trabalhadores em fatores econômicos e na modificação organizacional (BARBOSA, 2002).

Como um dos principais teóricos a respeito da cultura organizacional, Schein (1984) explica que esse constructo se trata da união de pressuposições elementares que um grupo de pessoas desvendou ou criou no momento em que aprenderam a resolver as dificuldades de adaptação externa ou interna, em que os resultados foram tão bons que passaram a ser vistos como válidos e, assim, foram repassados aos demais membros como a maneira certa de perceber, pensar e sentir essas questões. No campo da administração, a perspectiva de cultura frequentemente seguida é de que se trata de um sistema de representações simbólicas que possibilita maneiras comuns de perceber o mundo, tornando viável a comunicação entre os integrantes de um grupo (FLEURY, 1987). Ainda pode ser entendida como

[...] um conjunto de valores, expressos em elementos simbólicos e em práticas organizacionais, que em sua capacidade de ordenar, atribuir significações, construir a identidade organizacional, tanto agem como elementos de comunicação e consenso, como expressam e instrumentalizam relações de dominação" (FLEURY, 1995, p. 8).

O autor complementa que "a essência de uma cultura está no padrão das suposições básicas prevalecentes e, uma vez que alguém as entenda, é possível entender facilmente os níveis mais superficiais e lidar apropriadamente com eles" (SCHEIN, 2009 p. 33). Esse aspecto relaciona-se com o entendimento de Zago (2013), ao abordar que uma cultura organizacional se torna singular quando passa a ser delimitada por aspectos particulares e representativos dos seus membros e do seu estabelecimento no meio. Para o mesmo autor, tendo em vista a noção do determinismo gerado pela estrutura interna da cultura organizacional, infere-se que o comportamento nas organizações é a manifestação dos elementos estruturais internos e cognitivos. Contudo, sendo a cultura produto das vivências 


\section{CULTURA ORGANIZACIONAL DE UMA UNIVERSIDADE BRASILEIRA: UMA ANÁLISE DOS \\ VALORES E PRÁTICAS ORGANIZACIONAIS NA PERCEPÇÃO DOS DOCENTES \\ DOI: https://doi.org/10.5007/1983-4535.2021.e75461}

grupais dos integrantes da mesma, os comportamentos adotados pelos componentes da organização auxiliam no fortalecimento e consolidação da cultura.

A cultura organizacional é caracterizada por Zago (2013) como holográfica, já que possui e manifesta todos os níveis que fazem parte da mesma, desde o individual, passando pelo grupal, de classes, até o regional e o nacional. Segundo o autor, toda pessoa que faz parte de uma organização carrega uma bagagem cultural decorrente de suas vivências e, por essa razão, passa a refletir sua cultura local, que também decorre de outros níveis culturais de dimensões superiores, como o nacional, por exemplo.

Dias (2013) entende as organizações como culturas, abordando um cunho mais social do meio organizacional, mesmo que ainda se leve em conta os elementos formais. $\mathrm{O}$ autor subdivide as culturas organizacionais por setor, ou seja, a cultura do setor privado, do setor público e do terceiro setor e comenta que cada um desses tipos de organizações possuem uma cultura própria. Ainda, acrescenta que cada cultura organizacional é uma subcultura da cultura do país no qual a organização está instalada, já que os membros também fazem parte deste meio e compartilham seus principais valores. O autor enfatiza a importância de que os gestores saibam identificar os elementos da cultura nacional, tendo em vista que geram influência na constituição da identidade organizacional, pois muitos de seus valores elementares são decorrentes dos valores da própria sociedade. Porém, salienta ainda que muitos valores surgem apenas da organização, por sua maneira de realizar as funções, sua história e desenvolvimento, o que gera efeitos no comportamento dos seus membros, determinando seu estilo e filosofia dentro da organização.

Os ritos organizacionais são indicados por Costa (2014), que assim como os símbolos, acabam por estimular os valores que a organização espera que sejam praticados e instituídos. A autora comenta que a origem da cultura organizacional se dá já nos aspectos característicos dos fundadores da organização, como seus valores e a influência cultural de sua origem. Ainda, indica como influenciadores da cultura organizacional o tipo de produto ou serviço oferecido pela organização, o ambiente físico e a localização geográfica, o vestuário dos trabalhadores e o clima organizacional. Em relação às instituições públicas, a autora menciona o aspecto burocrático, tradicional dessas organizações, mas identifica que esse modo conservador da cultura organizacional em instituições públicas tem sido alterado.

Nas organizações sempre há uma cultura dominante - que se refere aos valores primordiais compartilhados pela maior parte dos integrantes - e subculturas, que são como 


\section{CULTURA ORGANIZACIONAL DE UMA UNIVERSIDADE BRASILEIRA: UMA ANÁLISE DOS \\ VALORES E PRÁTICAS ORGANIZACIONAIS NA PERCEPÇÃO DOS DOCENTES \\ DOI: https://doi.org/10.5007/1983-4535.2021.e75461}

pequenas culturas também imersas na organização, associadas à diferentes departamentos, unidades de negócio e até mesmo pela diferente localização geográfica dos membros. Uma cultura pode ser considerada forte quando os valores da organização estão arraigados e compartilhados por seus integrantes (BARBIERI, 2016). Nesse sentido, Bendassolli (2016) explica que o trabalho também é uma atividade que ocorre por intermédio dos sinais advindos da cultura, sendo assim, um fenômeno cultural.

A respeito dos elementos de uma cultura organizacional que auxiliam na consolidação da mesma, Barbieri (2016) destaca os rituais e cerimônias de homenagem ou premiação, assim como a corroboração dos valores e costumes, tanto a nível individual como grupal. A autora destaca que estudos indicam alguns aspectos que distinguem a cultura de uma empresa de sucesso ou não e cita a "inovação e liberdade para correr riscos; atenção aos detalhes; orientação para os resultados; orientação para as pessoas; orientação para a equipe; agressividade e não acomodação; estabilidade ou manutenção do status quo, em oposição à mudança e ao crescimento" (p. 122). Cabe salientar que a cultura organizacional se associa com a gestão do conhecimento, conforme indicado por Pérez e Rodríguez (2016), que indicam que uma organização deve buscar caracterizar-se por possuir uma cultura que estimula a geração e compartilhamento de conhecimento, assim como bom desempenho. Para os autores, isso faz com que os trabalhadores se sintam felizes, motivados e comprometidos com a organização.

A multidisciplinaridade para tratar a respeito da cultura organizacional é citada por Barale e Santos (2017), em função das muitas áreas que abordam essa temática nas pesquisas. Para Perez e Cobra (2017), as organizações assumem uma posição perante os desafios do meio em que estão inseridas de acordo com o processo cultural a que pertencem, utilizando as ferramentas que estão disponíveis em sua cultura. Os autores ainda mencionam que as empresas precisam desenvolver culturas específicas e gerais, que devem ser propagadas aos seus colaboradores, fornecedores e também aos acionistas.

Ao investigar a cultura organizacional em uma instituição de ensino superior privado utilizando o Instrumento Brasileiro para Avaliação da Cultura Organizacional (IBACO), de Ferreira et al. (2002), Just et al. (2018) identificaram que há uma boa relação da instituição com o público interno e com os discentes. No entanto, os autores alertam que para verificar com maior detalhamento as questões que fazem parte da cultura organizacional é necessária uma análise com maior profundidade. Frente ao exposto, tem-se como objetivo deste trabalho 


\section{CULTURA ORGANIZACIONAL DE UMA UNIVERSIDADE BRASILEIRA: UMA ANÁLISE DOS \\ VALORES E PRÁTICAS ORGANIZACIONAIS NA PERCEPÇÃO DOS DOCENTES \\ DOI: https://doi.org/10.5007/1983-4535.2021.e75461}

identificar a cultura organizacional de uma universidade brasileira. O método utilizado está descrito na seção abaixo, seguido dos resultados e discussão e das considerações finais.

\section{MÉTODO}

Esta pesquisa se trata de estudo de caso a partir da percepção dos docentes de uma universidade pública do sul do Brasil, com caráter descritivo, abordagem mista e natureza aplicada. A coleta e análise dos dados deu-se em dois momentos: uma etapa quantitativa e outra qualitativa. Para a coleta de dados quantitativos utilizou-se o Instrumento Brasileiro para Avaliação da Cultura Organizacional (IBACO) na versão reduzida (FERREIRA; ASSMAR, 2008), que é composta por 30 questões e conta com três fatores de valores (profissionalismo cooperativo, profissionalismo competitivo, satisfação e bem-estar dos empregados) e três fatores de práticas (integração externa, recompensa e treinamento, promoção do relacionamento interpessoal). Nesta etapa obteve-se 200 respondentes da escala, o que está adequado às orientações de Hair Jr. et al. (2009) quanto ao tamanho da amostra.

Para a realização das análises, tornou-se necessária a exclusão de quatro variáveis da IBACO, a fim de melhorar os valores das relações entre as dimensões em análises posteriores, em função de suas cargas fatoriais. Entre elas, uma se refere à "integração externa" (item "os chefes imediatos são como pais para os docentes"), outra à "promoção do relacionamento interpessoal” (item "as inovações são em geral introduzidas para atender às necessidades do mercado") e ainda duas variáveis referentes ao "profissionalismo competitivo" (item "a competição é valorizada, mesmo que de forma não sadia, porque o objetivo maior da instituição é a produtividade" e "a competição é vista como indispensável à obtenção de bons resultados").

Dessa maneira, realizou-se análises de estatística descritiva utilizando o software Statistical Package for the Social Sciences (SPSS) versão 21.0 e a Padronização de Escalas segundo Lopes (2018), transformando os dados, antes organizados em escala ordinal, em escala de razão de 0 a 100\%, e de maneira proporcional os resultados, a partir da escala likert de 5 pontos passaram a ser classificados como indicadores a partir do critério "baixo" (0 a 1,67), "moderado" (1,68 a 3,33) e "alto" (3,34 a 5). Para a coleta dos dados qualitativos, utilizou-se entrevistas com 8 docentes, que foram analisadas seguindo o método de análise de conteúdo proposta por Bardin (2016), seguindo as categorias descritas no Quadro 1. 


\section{CULTURA ORGANIZACIONAL DE UMA UNIVERSIDADE BRASILEIRA: UMA ANÁLISE DOS \\ VALORES E PRÁTICAS ORGANIZACIONAIS NA PERCEPÇÃO DOS DOCENTES \\ DOI: https://doi.org/10.5007/1983-4535.2021.e75461}

Quadro 1 Categorias da análise de conteúdo da pesquisa.

\begin{tabular}{lcc}
\hline \multicolumn{1}{c}{ Categorias iniciais ou subcategorias } & Categorias intermediárias & Categoria final \\
\hline Existência de cooperação & Profissionalismo cooperativo & \\
Valorização da cooperação & Profissionalismo competitivo & \\
Competitividade & Satisfação e bem-estar dos empregados & Cultura \\
Satisfação e bem-estar dos docentes & Integração externa & Organizacional \\
$\begin{array}{l}\text { Relações interpessoais com os estudantes } \\
\text { Preocupação com o atendimento das } \\
\text { necessidades dos estudantes }\end{array}$ & & \\
$\begin{array}{l}\text { Recompensa } \\
\text { Treinamento }\end{array}$ & Recompensa e treinamento & \\
Relações interpessoais no trabalho & Promoção do relacionamento interpessoal & \\
\hline
\end{tabular}

Fonte: elaborado pelos autores com base em Ferreira e Assmar (2008).

A partir das análises propostas, elaborou-se os resultados e a discussão das mesmas, apresentadas na seção que segue.

\section{RESULTADOS E DISCUSSÃO}

Em relação ao perfil da amostra dos participantes da pesquisa, houve um predomínio de docentes do gênero feminino (54\%). A maior parte dos docentes participantes possui entre 51 a $60 \operatorname{anos}(32 \%)$, os que possuem entre 31 a 40 anos são $27,5 \%$ e os que possuem entre 41 a 50 anos são $25 \%$. Há um percentual menor de docentes que estão com mais de 61 anos e (11\%) e até 30 anos (4,5\%). Em relação ao estado civil, a maioria dos pesquisados eram casados ou possuíam união estável $(69,5 \%)$ e $62,5 \%$ dos participantes possuem filhos. Quanto aos dados ocupacionais, a maior parte dos docentes possui doutorado (67\%) e têm mais de 15 anos de carreira $(48,5 \%)$, com renda entre 11 a 15 salários mínimos $(55 \%)$ e carga horária semanal correspondente a 40 horas $(70,5 \%)$.

Para identificar a cultura organizacional da universidade analisada, apresenta-se inicialmente os fatores de valores que correspondem ao: profissionalismo cooperativo, profissionalismo competitivo, satisfação e bem-estar dos empregados. Na sequência, apresenta-se os fatores de práticas, que se referem a: integração externa, recompensa e treinamento e promoção do relacionamento interpessoal. O primeiro fator apresentado se refere ao "profissionalismo cooperativo" o qual compreende a valorização dos funcionários que realizam suas atividades de maneira competente, apresentam espírito colaborativo e capacidade de iniciativa, tendo em vista os objetivos da organização são os aspectos que compõem o item profissionalismo cooperativo (FERREIRA; ASSMAR, 2008). A partir dos dados quantitativos sobre a percepção dos docentes a respeito desse fator, a Tabela 1 descreve o resultado dessa avaliação para cada item do questionário. 


\section{CULTURA ORGANIZACIONAL DE UMA UNIVERSIDADE BRASILEIRA: UMA ANÁLISE DOS VALORES E PRÁTICAS ORGANIZACIONAIS NA PERCEPÇÃO DOS DOCENTES \\ DOI: https://doi.org/10.5007/1983-4535.2021.e75461}

Tabela 1 Média, desvio padrão e classificação dos itens do fator profissionalismo cooperativo

\begin{tabular}{|c|c|c|c|}
\hline Itens & Média & Desvio Padrão & Classificação \\
\hline $\begin{array}{l}\text { Os docentes que demonstram dedicação e espírito de colaboração são os } \\
\text { melhores modelos a serem seguidos. }\end{array}$ & 3,77 & 1,128 & \multirow{4}{*}{ ALTO } \\
\hline A preocupação do docente com a qualidade de seu serviço é bem vista. & 3,53 & 1,051 & \\
\hline O profissionalismo dos docentes é visto como uma grande virtude. & 3,46 & 1,133 & \\
\hline $\begin{array}{l}\text { A preocupação em superar as dificuldades do dia-a-dia é vista como de } \\
\text { grande valor. }\end{array}$ & $\begin{array}{c}3,37 \\
5\end{array}$ & 1,077 & \\
\hline $\begin{array}{l}\text { O esforço e a dedicação ao trabalho são qualidades bastante apreciadas. } \\
\text { Profissionalismo Cooperativo }\end{array}$ & $\begin{array}{r}3,27 \\
68,35\end{array}$ & $\begin{array}{c}1,132 \\
18,643\end{array}$ & $\begin{array}{l}\text { MODERADO } \\
\text { ALTO }\end{array}$ \\
\hline
\end{tabular}

Fonte: Dados da pesquisa (2019).

Com base na Tabela 1 observa-se que as médias variaram entre 3,2 e 3,7 o que indica que os docentes percebem que os itens relacionados ao profissionalismo cooperativo se aplicam em parte em sua instituição. Todos os itens classificaram-se como alto, com exceção do item "o esforço e a dedicação ao trabalho são qualidades bastante apreciadas", que obteve média 3,2 e por isso, enquadra-se como moderado. As avaliações de cada item do fator profissionalismo cooperativo auxiliam a compreender melhor a percepção dos docentes quanto a essa prática em sua instituição. Por meio da padronização das escalas verificou-se entre os docentes que consideram como alto o fator "profissionalismo cooperativo" (50\%), como moderado (40\%) e como baixo (5\%). Dessa maneira, entende-se que a universidade brasileira pesquisada classifica o profissionalismo cooperativo entre moderada a superior, configurando-se como uma avaliação positiva quanto para este fator.

Os dados quantitativos obtidos na pesquisa são corroborados pelos dados qualitativos, uma vez que, nas falas dos docentes são ressaltadas suas percepções positivas e negativas sobre o profissionalismo cooperativo. A primeira categoria de análise diz respeito à "existência de cooperação", em que quatro dos oito docentes mencionaram nas entrevistas que percebem existir cooperação no ambiente de trabalho enquanto que dois apontaram aspectos mais negativos. A fim de demonstrar as falas referentes a esta categoria, menciona-se exemplos do que foi relatado pelos docentes quanto a esse aspecto:

[...] inclusive o chefe do departamento ele não é eleito com os coordenadores... aí cada um faz como quer, aí é uma pergunta você faz o que tu quer, eu sou mais coletivo [...] O departamento não sabe o que dirige, ele só escuta as pessoas e parece que tá bom, mas não, não tem uma meta[...] (BR2).

[...] eu sinto que também no pequeno grupo de colegas, de professores, falando especificamente dos docentes, as pessoas compartilham as conquistas né, compartilham as vitórias [...] (BR6). 


\section{CULTURA ORGANIZACIONAL DE UMA UNIVERSIDADE BRASILEIRA: UMA ANÁLISE DOS \\ VALORES E PRÁTICAS ORGANIZACIONAIS NA PERCEPÇÃO DOS DOCENTES \\ DOI: https://doi.org/10.5007/1983-4535.2021.e75461}

A partir dos dados observa-se que, de maneira geral, os docentes participantes afirmam existir colaboração, ainda que alguns professores participem menos, tendo em vista que não existe uma cobrança por parte da instituição quanto a isso. Também relatam como pontos positivos a troca entre os grupos de pesquisa, a busca por manter a tradição e fazer um curso o melhor possível, em que citam a preocupação da Pró-Reitoria em fazer com que o planejamento estratégico da instituição fosse pensado colaborativamente com os docentes.

Como ponto negativo apresentado por um dos docentes é a menção de que a eleição do chefe do departamento deveria contar com a participação dos coordenadores de curso. Ainda que hajam algumas observações feitas pelos docentes que se apresentam como possíveis espaços para melhorias, a avaliação dos participantes brasileiros quanto à existência de colaboração no ambiente de trabalho foi positiva. A segunda categoria de análise qualitativa é a "valorização da cooperação" na qual dos oito docentes brasileiros somente um percebe que de alguma forma há certa valorização da cooperação no meio universitário.

Do ponto de vista institucional tem muito fator político né em cima disso então depende muito da situação, da posição que tu se posiciona [...] Mas existe também, por exemplo, a premiação dos 10 anos de INSTITUIÇÃO, 20 anos, 30 anos, então é algo que parece muito singelo, mas é relevante, as pessoas se sentem acolhidas, valorizadas [...] (BR6).

$\mathrm{Eu}$ vejo isso muito de forma informal, imaterial, eu não vejo por exemplo a vou dar um parabéns, vou isso...eu não vejo. [...] por exemplo, tu tem que dizer pra instituição que teu trabalho foi premiado [...]cara, só um pouquinho, alguma coisa tá na contra mão [...] (BR8).

Em relação a valorização da cooperação, constata-se que os docentes brasileiros percebem que a valorização não se dá diretamente por meio de ações realizadas pela instituição, mas sim pelo meio externo e pelos próprios docentes e estudantes que reconhecem o seu trabalho e o procuram para participação em bancas, pesquisas ou mesmo trocas entre grupos de pesquisa. Também percebem essa visibilidade por parte de outras instituições que não a sua própria e citam o enaltecimento dos grupos que conseguem financiamento com serviços, em que enfatizam a falta de valorização das licenciaturas, que deve emergir da própria universidade. Nesse cenário, preocupa a fala do BR8 que relata que "a universidade federal é o melhor lugar do mundo pra se trabalhar, se você quer trabalhar, mas é o melhor lugar no mundo para não trabalhar”, em que percebe-se por meio da fala que parece existir uma falta de controle por parte da instituição sobre a atuação dos docentes. 


\section{CULTURA ORGANIZACIONAL DE UMA UNIVERSIDADE BRASILEIRA: UMA ANÁLISE DOS \\ VALORES E PRÁTICAS ORGANIZACIONAIS NA PERCEPÇÃO DOS DOCENTES \\ DOI: https://doi.org/10.5007/1983-4535.2021.e75461}

A partir disso, entende-se que os docentes percebem que há cooperação entre colegas da instituição, mas não há um consenso sobre a valorização dessas atitudes. Ao encontro das falas dos participantes, Lorentziadis (2002) já apontava a relevância da cooperação nas organizações, pois mesmo em meios em que a competição é instigada, esse incentivo só tem efeitos otimizados se existir a noção de priorização da cooperação à competição, indicando que a competição é eficaz desde que esteja em um meio predominado pela cooperação.

O segundo fator apresentado se trata do "profissionalismo competitivo" no qual enfatiza-se a valorização do desempenho individual a fim de alcançar as metas, mesmo que para isso seja necessário "passar por cima" de colegas que possuem metas parecidas (FERREIRA; ASSMAR, 2008). Considerando essa definição, a Tabela 2 permite analisar as médias dos itens relacionados a esse fator, bem como suas respectivas classificações.

Tabela 2 Média, desvio padrão e classificação dos itens do fator profissionalismo competitivo

\begin{tabular}{lccc}
\hline \multicolumn{1}{c}{ Itens } & Média & Desvio Padrão & Classificação \\
\hline $\begin{array}{l}\text { O crescimento profissional é considerado indispensável à } \\
\text { permanência do docente na instituição }\end{array}$ & 2,835 & 1,336 & MODERADO \\
$\begin{array}{l}\text { A criatividade é um dos requisitos básicos para a ocupação de } \\
\text { cargos gerenciais. }\end{array}$ & 2,52 & 1,177 & 1,117 \\
$\begin{array}{l}\text { Somente os bons docentes recebem benefícios que lhes } \\
\text { garantem um melhor bem-estar }\end{array}$ & 2,305 & 20,258 & \\
Profissionalismo Competitivo & 47,57 & 25 \\
\hline
\end{tabular}

Fonte: Dados da pesquisa (2019).

A partir da Tabela 2 constata-se que todos os itens foram classificados como moderado, com médias entre 2,3 e 2,8, o que indica uma percepção equilibrada a respeito desse fator na percepção dos docentes. Isso pode demonstrar um aspecto positivo, já que nos estudos de França (2006), a competitividade em equipes de trabalho pode ser positiva quando favorece o aumento da produtividade, mas esses benefícios podem ser inferiores aos prejuízos da competição no ambiente de trabalho.

A partir da padronização das escalas verificou-se entre os docentes brasileiros que consideram como moderado o fator "profissionalismo competitivo" (46,5\%). No entanto, também se apresenta dados significativos nas classificações como alta $(28,5 \%)$ e baixa $(25 \%)$. $\mathrm{O}$ resultado moderado como mais expressivo caracteriza-se como um aspecto positivo, pois uma competitividade alta no ambiente de trabalho não é benéfica, tampouco baixa, tendo em vista que é importante para galgar melhores resultados organizacionais.

Os dados quantitativos podem ser melhor esclarecidos a partir das análises qualitativas, uma vez que nelas os docentes esclarecem alguns pontos importantes. Referente 


\section{CULTURA ORGANIZACIONAL DE UMA UNIVERSIDADE BRASILEIRA: UMA ANÁLISE DOS \\ VALORES E PRÁTICAS ORGANIZACIONAIS NA PERCEPÇÃO DOS DOCENTES \\ DOI: https://doi.org/10.5007/1983-4535.2021.e75461}

a categoria de análise "competitividade", sete dos oito docentes comentaram que há certa competitividade no local de trabalho, no entanto uns percebem de maneira positiva ou neutra, enquanto outros ressaltam os aspectos negativos dessa competitividade, como o contido nos exemplos.

Se a competitividade fosse saudável é uma coisa, uma competitividade por criticar o trabalho do colega assim não me satisfaz [...] tem lugares que é pior... não sei se alguém já te disse isso, eu quis ser professor, o pesquisador veio porque te obriga pela competitividade[...] (BR4).

Aqui no departamento [...] talvez nós estamos engatinhando na pósgraduação [...]Não há tanta competitividade quanto a isso né [...] (BR5).

Velada, por um lado não se quer né, porque é feio ser competitivo é tal e por outro lado é velada, mas velada não de querer ser melhor, na questão de eu quebrar quem é melhor [...] (BR8).

Ao analisar a fala dos docentes brasileiros, a competitividade aparece mais fortemente atrelada à pesquisa. $\mathrm{Na}$ fala do $\mathrm{BR} 4$, este relata a origem desse comportamento em função da atividade como pesquisador: "eu quis ser professor, o pesquisador veio porque te obriga pela competitividade”. Os pilares da universidade brasileira se baseiam no ensino, pesquisa e extensão e por isso, a mesma estimula os docentes na carreira como pesquisadores. Os relatos indicam que os docentes associam a competitividade aos grupos de pesquisa, para a obtenção de um maior número de orientandos e pela necessidade de captação de recursos. Com isso, constata-se que, segundo esses participantes, esse fator não é percebido de maneira tão positiva, ainda que haja a menção de que certo nível de competitividade é tolerável e até desejado.

Ao associar a competitividade à pesquisa, o BR4 aponta como fator a busca por produtividade acadêmica, ou seja, relacionada a publicações de artigos, orientações, projetos. Esse sistema produtivista recebe críticas de diversos autores, como Bossi (2007), que já salientava que essa produtividade traz recompensas financeiras e simbólicas, ao mesmo tempo que gera perda da autonomia intelectual e do controle relacionado ao método de trabalho, fazendo com que o trabalho intelectual se associe à lógica do capital.

Lemos (2011) enfatiza que o incentivo do Estado para que os docentes coloquem em foco as atividades de pesquisador por meio de recursos e gratificações faz com que o ensino passe a ser percebido como menos importante. Isso fomenta a competição entre os pares, trazendo como consequências o enfraquecimento dos vínculos entre os docentes e a criação de 


\section{CULTURA ORGANIZACIONAL DE UMA UNIVERSIDADE BRASILEIRA: UMA ANÁLISE DOS \\ VALORES E PRÁTICAS ORGANIZACIONAIS NA PERCEPÇÃO DOS DOCENTES \\ DOI: https://doi.org/10.5007/1983-4535.2021.e75461}

conflitos no meio laboral, que pode interferir negativamente no clima organizacional e, portanto, não beneficia a integração do conhecimento.

O produtivismo acadêmico é compreendido por Patrus, Dantas e Shigaki (2015) como um derivado da avaliação da pós-graduação, que valoriza demasiadamente a quantidade da produção acadêmica. Esses autores apontam para a possibilidade de o produtivismo afetar a solidariedade entre os pares na academia, já que desfavorece a percepção da importância da união e cooperação entre os docentes. Como possibilidades para solucionar ou amenizar esta questão, os autores sugerem a busca pelo atendimento das exigências de avaliação da Capes sem levá-las ao extremo, com avaliação dos docentes de um programa a partir do desempenho do grupo e não por seus resultados individuais

O terceiro fator analisado, "satisfação e bem-estar dos empregados", os quais referemse à busca pelo bem-estar, satisfação e motivação dos funcionários, visando tornar o ambiente de trabalho mais humano, agradável e prazeroso (FERREIRA; ASSMAR, 2008). As avaliações referentes a esse fator constam na Tabela 3.

Tabela 3 Média, desvio padrão e classificação dos itens do fator satisfação e bem-estar dos empregados

\begin{tabular}{|c|c|c|c|}
\hline Itens & Média & Desvio Padrão & Classificação \\
\hline Investe-se no crescimento profissional dos docentes. & 3,66 & 1,063 & \\
\hline $\begin{array}{l}\text { As necessidades pessoais e o bem-estar dos docentes } \\
\text { constituem uma preocupação constante da instituição. }\end{array}$ & 3,51 & 0,935 & ALTO \\
\hline $\begin{array}{l}\text { Os docentes recebem treinamento para poderem desenvolver } \\
\text { sua criatividade. }\end{array}$ & 2,735 & 1,127 & \\
\hline $\begin{array}{l}\text { Programas para aumentar a satisfação dos docentes são } \\
\text { regularmente desenvolvidos. }\end{array}$ & 2,52 & 1,079 & \\
\hline $\begin{array}{l}\text { Programas destinados a melhorar o bem-estar dos docentes são } \\
\text { implementados e testados. }\end{array}$ & 2,485 & 1,06 & MODERADO \\
\hline Satisfação e Bem-Estar dos Empregados & 57,958 & 17,703 & \\
\hline
\end{tabular}

Fonte: Dados da pesquisa (2019).

Nas avaliações dos itens de acordo com a Tabela 3, observa-se que as médias ficaram em torno de 3,5 e 3,6 (para dois itens) classificadas como alto e entre 2,4 a 2,7 (para três itens) classificados como moderado. $\mathrm{Na}$ padronização das escalas, a classificação mais com percentual mais expressivos é como moderada (57,5\%), seguido da classificação como alta (30\%) com índices menores para a classificação como baixa (12,5\%).

Considerando os dados da padronização das escalas e da Tabela 4, essas informações parecem estar alinhadas com os dados qualitativos, já que entre os docentes brasileiros, dois percebem que não existem essas práticas, outros dois docentes apontam que ainda há muitas 


\section{CULTURA ORGANIZACIONAL DE UMA UNIVERSIDADE BRASILEIRA: UMA ANÁLISE DOS \\ VALORES E PRÁTICAS ORGANIZACIONAIS NA PERCEPÇÃO DOS DOCENTES \\ DOI: https://doi.org/10.5007/1983-4535.2021.e75461}

possibilidades de melhorias, já que indicam certo distanciamento e precariedades. Os outros quatro percebem que essas práticas que visam a satisfação e bem-estar dos docentes acontecem e são preocupações da instituição, ainda que exista alguns pontos que não estejam totalmente atendidos. Esses dados são exemplificados por meio das falas dos docentes BR5, BR7 e BR8.

A preocupação existe né, [...] cada professor tem sua sala, cada professor tem uma escrivaninha, cada um tem um computador né, tem uma mesa de reuniões em cada sala, quer dizer o espaço é ótimo (BR5).

Eu vejo um distanciamento, [...] o departamento poderia ter ações vinculadas a própria PROGEP, informar, externalizar isso para os professores, trazer os professores mais próximos (BR7).

[...] como é que tu sabe que eu sou professor, cadê a minha identificação [...] Eu fui designado pra dar uma aula lá na farmácia, [...]mas eu chego lá eu peço assim [...] Eu quero a chave por favor, não tem identidade, não tem crachá, não tem nada (BR8).

Considerando os exemplos das falas dos docentes brasileiros, parece existir uma preocupação com a satisfação e bem-estar dos docentes por parte da instituição, mas não é algo tão evidente. Dentre as práticas mencionadas estão: o centro voltado para qualidade de vida do servidor, e-mails que lembram sobre acompanhamento médico, a própria existência da Pró-Reitoria de Gestão de Pessoas. Além disso, como cita o BR5, "pra ministrar aula é um prédio novo... cada professor tem sua sala, cada professor tem uma escrivaninha, cada um tem um computador, tem uma mesa de reuniões em cada sala, quer dizer o espaço é ótimo". Logo, percebe-se que as instalações em que os docentes trabalham são adequadas e que existem ações que buscam o bem-estar dos docentes, apesar de haver um distanciamento entre os docentes e a instituição em relação a essas práticas.

Em vista disso, constata-se que a universidade deve buscar meios de divulgar e esclarecer essas atividades para os docentes. Salienta-se o comentário do BR7, o qual propõe uma solução interessante, de aproximação das ações da PROGEP, mudando o foco das ações. O docente sugere que essas atividades não sejam a nível institucional e, sim, numa escala menor, em que relata que: "eu acho que isso tinha que ser num nível menor em termos de departamento né... o departamento poderia ter ações vinculadas a própria PROGEP, informar, externalizar isso para os professores, trazer os professores mais próximos”. Com isso, parece que relevante que a universidade pense alternativas para deixar essas ações mais claras e disponíveis para os docentes para que possam acessar esses meios de cuidado. 


\section{CULTURA ORGANIZACIONAL DE UMA UNIVERSIDADE BRASILEIRA: UMA ANÁLISE DOS \\ VALORES E PRÁTICAS ORGANIZACIONAIS NA PERCEPÇÃO DOS DOCENTES \\ DOI: https://doi.org/10.5007/1983-4535.2021.e75461}

Os comentários indicam elementos positivos, tendo em vista que existem as ações, mas parece necessário aperfeiçoar o elo de ligação entre o que é oferecido pela universidade e o que os docentes percebem como disponível, ou seja, mais divulgações e informações. Marqueze e Moreno (2005) explicam que o modo como se apresenta a satisfação no trabalho pode ser um fator promotor de saúde ou um elemento que gera danos à mesma, trazendo insatisfação e aborrecimentos à própria organização e ao meio laboral. A fim de evitar consequências negativas geradas pela insatisfação com o trabalho, os autores apontam que existem possibilidades e estratégias a serem utilizadas para favorecer a saúde no ambiente organizacional, como por exemplo: o ajustamento do trabalhador a sua função, fomento do lazer, esportes, relaxamento e atividades que promovam a sociabilidade, salários compatíveis com a função, entre outros elementos existentes nesse processo.

Ademais, Amaral, Borges e Juiz (2017), advertem que a saúde no trabalho dos docentes é fundamental para qualidade do ensino e salientam a importância de evitar que o engajamento e o prazer em trabalhar não sejam prejudicados pela precarização do ensino superior público que acontece no contexto brasileiro. Finalizadas as análises sobre os fatores de valor da cultura organizacional, aborda-se sobre os fatores de práticas.

O primeiro fator de práticas organizacionais analisado refere-se à "integração externa" o qual diz respeito às práticas relacionadas ao planejamento estratégico, tomada de decisões e ao receptor do serviço prestado (FERREIRA; ASSMAR, 2008), que neste estudo se referem aos estudantes. Por meio dos dados quantitativos sobre a percepção dos docentes sobre esse fator, na Tabela 4 são descritos os resultados dessa avaliação para cada item do questionário.

Tabela 4 Média, desvio padrão e classificação dos itens do fator integração externa

\begin{tabular}{lccc}
\hline \multicolumn{1}{c}{ Itens } & Média & Desvio Padrão & Classificação \\
\hline Mantêm-se relações amigáveis com os alunos. & 4,23 & 0,706 & \\
O atendimento às necessidades dos alunos é uma das metas & 4,09 & 0,892 & ALTO \\
mais importantes. & & 0,982 & \\
$\begin{array}{l}\text { Persegue-se a excelência de produtos e serviços como forma de } \\
\text { satisfazer aos alunos. }\end{array}$ & 3,745 & & 0,88 \\
O acompanhamento e atendimento das necessidades dos alunos & 3,67 & 14,406 & \\
é feito constantemente. & 77,552 & \\
Integração Externa &
\end{tabular}

Fonte: Dados da pesquisa (2019).

Na Tabela 4 infere-se que a avaliação da percepção a respeito desse fator é positiva, já que as médias estão entre 3,6 e 4,2, remetendo a uma concordância dos docentes com as afirmativas. Esse fator apresenta-se como o mais bem avaliado pelos docentes brasileiros. Por meio da padronização das escalas verificou-se uma maior porcentagem para a classificação 


\section{CULTURA ORGANIZACIONAL DE UMA UNIVERSIDADE BRASILEIRA: UMA ANÁLISE DOS \\ VALORES E PRÁTICAS ORGANIZACIONAIS NA PERCEPÇÃO DOS DOCENTES \\ DOI: https://doi.org/10.5007/1983-4535.2021.e75461}

como alta (82\%) seguido da classificação moderada (30\%) e apenas $1 \%$ dos docentes brasileiros entendem como baixa a avaliação desse fator. Vale mencionar que existem menções de pontos a serem melhorados nas análises qualitativas para esse fator, o qual foi organizado em duas subcategorias. A primeira se refere as relações interpessoais com os estudantes, enquanto a segunda diz respeito a preocupação com o atendimento das necessidades dos mesmos.

Nas análises referentes às "relações interpessoais com os estudantes", os participantes indicaram uma boa relação, ainda que existam algumas questões a serem repensadas ou resolvidas no que se refere ao corpo discente, o que pode ser verificado nas falas transcritas:

Eu acho que é boa, é boa, os alunos geralmente né têm pouca reclamação de professor, de atitudes né, que isso era uma preocupação antes, já tivemos problemas desses tipos de relacionamento (BR2).

Eu acho boa né, claro como sempre não vai agradar todo mundo, impossível $[\ldots]$ tem grandes amigos ou acho que são amigos os alunos né, [...] o nosso curso é ainda bem, há uma grande relação entre docentes e os alunos acadêmicos, é boa a relação né, claro problemas tem, mas grandes não tem [...] (BR5).

Tais relatos indicam uma boa relação dos docentes com os discentes, ainda que possam existir exceções em determinados momentos. Cabe destacar que um docente relatou que percebe que alguns estudantes têm receio de falar com os docentes ou tecerem comentários, enquanto outro percebe que em algum momento a relação ficou "fria", indicando pontos de fragilidade.

Uma crítica feita pelo BR5 é a respeito da avaliação institucional do docente pelo estudante, em que relata que "essa avaliação acontece durante a segunda avaliação do semestre e aí eu vejo um pouco de viés claro que isso depende da maturidade do aluno, um pouco de viés na resposta do aluno, aquele aluno que foi bem na segunda avaliação e que não pegou exame, elogia o professor né, aquele aluno que pegou exame e não foi bem na avaliação as vezes faz críticas desnecessárias ao docente”. O BR2 também questiona essa avaliação: "se avalia o docente pelo discente, me desculpe não é um critério legal, porque o discente ele vai avaliar um docente pelo o que?". As falas indicam a possibilidade de existirem conflitos entre os docentes e estudantes a partir da avaliação institucional dos profissionais e por isso, esse aspecto pode ser tema de investigações futuras. 
$\mathrm{Na}$ segunda subcategoria de análise, a "preocupação com o atendimento das necessidades dos estudantes", três docentes mencionaram essa preocupação, conforme os exemplos:

Temos que ter a compreensão que nem sempre a aprendizagem é homogênea na turma, é heterogênea [...] tem alunos com maior dificuldade, então nós temos que ter a percepção dessa heterogeneidade e receber o aluno e orientar ele fora da sala de aula, para que ele tenha condições de acompanhar a turma também [...] (BR5).

Eu tenho que tá sempre estudando, eu tenho que tá sempre me auto avaliando pra que eu consiga atender as demandas dos novos alunos, com outra cabeça, outra geração e também com os novos conhecimentos que existem né, então essa questão é um desafio eterno de habilidade (BR6).

[...] é me dedicar cada dia mais, eu vejo assim, eu não costumo ir pra uma sala de aula sem me preparar, embora eu já tenha 10 anos de experiência mas todas as minhas aulas eu sempre preparo, estudo, leio e busco alternativas de diferenciá-las (BR7).

Ao analisar tal categoria verifica-se a preocupação dos docentes com o atendimento das necessidades dos estudantes, os quais reconhecem e consideram a heterogeneidade da turma no processo de aprendizagem. A preocupação em capacitar-se para atingir os objetivos da docência é mencionada pelos docentes, ao citarem a necessidade de atentar para a própria formação e atualização, com busca por novos conhecimentos a fim proporcionar boas aulas e atender a demanda dos estudantes de uma maneira atual, visando a transformação da educação.

Esse aspecto é ressaltado por Vieira-Santos e Henklain (2017), que ressaltam a importância da relação entre docentes e estudantes no processo de ensino/aprendizagem, objetivo principal do trabalho do professor. Os desafios da docência são mencionados por Canan e Santos (2019), que relatam a necessidade de atualização da formação, dos conhecimentos e dos posicionamentos para que se tenha embasamento teórico, metodológico e prático para o aperfeiçoamento da prática docente e, consequentemente, a manutenção da qualidade do processo de ensino e aprendizagem.

$\mathrm{O}$ segundo fator de práticas organizacionais pesquisado refere-se a "recompensa e treinamento", que visa atender os clientes internos - ou seja, os colaboradores - quanto às práticas da instituição quanto a esses dois elementos (FERREIRA; ASSMAR, 2008). Tendo isso em vista, na Tabela 5 são apresentadas as médias, desvios padrão e classificação dos itens do fator recompensa e treinamento. 


\section{CULTURA ORGANIZACIONAL DE UMA UNIVERSIDADE BRASILEIRA: UMA ANÁLISE DOS \\ VALORES E PRÁTICAS ORGANIZACIONAIS NA PERCEPÇÃO DOS DOCENTES \\ DOI: https://doi.org/10.5007/1983-4535.2021.e75461}

Tabela 5 Média, desvios padrão e classificação dos itens do fator recompensa e treinamento

\begin{tabular}{lccc}
\hline \multicolumn{1}{c}{ Itens } & Média & Desvio Padrão & Classificação \\
\hline $\begin{array}{l}\text { Os docentes que apresentam ideias inovadoras costumam ser } \\
\text { premiados. }\end{array}$ & 2,985 & 1,014 & 1,111 \\
$\begin{array}{l}\text { As inovações costumam ser introduzidas através de programas } \\
\text { de qualidade. }\end{array}$ & 2,51 & 1,112 & MODERADO \\
$\begin{array}{l}\text { Os docentes são premiados quando apresentam um } \\
\text { desempenho que se destaca dos demais }\end{array}$ & 2,405 & 0,989 & \\
$\begin{array}{l}\text { Os docentes costumam ser premiados quando alcançam metas } \\
\text { pré-estabelecidas. }\end{array}$ & 1,92 & 0,946 \\
$\begin{array}{l}\text { Eventos sociais com distribuição de brindes são comumente } \\
\text { realizados para os docentes. }\end{array}$ & 1,815 & 17,678 \\
\hline Recompensa e Treinamento & 44,312 & \\
\hline
\end{tabular}

Fonte: Dados da pesquisa (2019).

Os dados da Tabela 5 variando entre 1,8 e 2,9 apontam para uma percepção dos docentes de que a existência de práticas de recompensa e treinamento estão entre pouco se aplica e aplica-se razoavelmente, indicando um resultado moderado para esse fator. A padronização das escalas indicou para esse fator classificação de moderado a baixo, com poucos docentes classificando-o como alto $(8 \%)$.

As razões para essa classificação podem ser observadas nas falas dos docentes. Para essa avaliação, utilizou-se duas subcategorias de análise "recompensas" e "treinamentos". No tocante às "recompensas", três docentes brasileiros percebem esse fator de maneira negativa e três de maneira positiva, conforme alguns exemplos das falas:

De recompensa é [...] mais pessoal do que em termos recompensatórios financeiros, porque não tem como tu ser recompensado, porque o teu salário é aquilo ali, [...] mas então tu não tem recompensas (BR4).

Eu penso que tem, por exemplo, quando eu vou pra um evento e que eu tenho subsídios financeiros eu já considero isso uma recompensa e tanto, porque senão teria que tirar do bolsa e tal, eu considero um benefício indireto bem importante, então desse ponto de vista financeiro e além disso tem oportunidades de trabalhos adicionais que também tem uma recompensa financeira adicional, projetos de todos os tipos, de extensão, de pesquisa, até Cnpq, Fapergs que tu também recebe benefícios pra compra de equipamento (BR6).

Ao analisar a fala dos docentes percebe-se que os mesmos salientam as recompensas pessoais, já que recompensas financeiras não são possíveis em função da instituição ser pública. O que acontece são mais subsídios financeiros para participação em eventos, que podem ser considerados como um benefício indireto, além das progressões previstas no regime de servidor público. Também relataram o fato dessas recompensas serem esporádicas e não auto realimentadas 


\section{CULTURA ORGANIZACIONAL DE UMA UNIVERSIDADE BRASILEIRA: UMA ANÁLISE DOS \\ VALORES E PRÁTICAS ORGANIZACIONAIS NA PERCEPÇÃO DOS DOCENTES \\ DOI: https://doi.org/10.5007/1983-4535.2021.e75461}

O BR8 faz uma crítica a respeito dos auxílios financeiros para a participação em eventos, quando comenta: "ano passado a gente passou em evento lá na Suécia, a gente não foi porque conseguia um troquinho aqui, um troquinho ali, pires na mão e não dá [... Pagar para trabalhar não dá né [...]". Essa expressão de "andar com o pires na mão" também foi mencionada por Tavares (2010) a respeito dos docentes na busca por recursos para pesquisas, indicando o movimento de precarização do trabalho e sucateamento das IES públicas no Brasil.

Além das recompensas, as práticas de treinamento também foram analisadas. $\mathrm{Na}$ percepção dos docentes a esse respeito, os oito docentes brasileiros percebem que existem práticas de treinamentos, ainda que apontem possíveis melhorias. São citadas falas que exemplificam esse cenário:

[...] o pós-doc é um treinamento, é uma qualificação? [...] tu tens o apoio, eu tive bolsa, eu não iria morar na Europa sem bolsa. A INSTITUIÇÃO dá todo o apoio, tu não perde a progressão, tu tem o teu salário, como se tu estivesse trabalhando, tu tem direito a férias, então assim tu tem tudo então... eu recebo por e-mail da PROGEP, assim mas eu não [...] a única coisa que eu fiz foi no idioma sem fronteiras (BR4).

[...] treinamento também, puxa só não participo mais porque não quero ou não consigo, mas existe possibilidades de envolvimento, de capacitação, de possibilidades até mesmo fora da instituição, com algum auxílio da própria instituição, eu percebo que tem (BR6).

Com base nas falas dos docentes, a universidade brasileira parece disponibilizar e preocupar-se em fornecer treinamentos para seus docentes. Foram citadas pelas docentes formações sobre novas metodologias, uso da tecnologia, de recursos pedagógicos, do moodle, idioma sem fronteiras, orientação pedagógica, capacitações fora da instituição, pós-doutorado e ainda relataram receber e-mails da PROGEP com ofertas de treinamentos. No entanto, parece existir pouca adesão dos docentes para com esses treinamentos, logo, há necessidade de considerar estratégias que instiguem os professores a realizarem os mesmos, já que são importantes para a atualização constante do corpo docente, assim como possibilitam aprendizados de novas ferramentas e conhecimentos que influenciam diretamente na maneira como as aulas e demais atividades dos docentes são realizadas.

A importância do treinamento contínuo dos docentes é explicada a partir da percepção de Pachane e Pereira (2004), que relatam que os elementos requeridos aos docentes do ensino superior ultrapassam o conhecimento do assunto o qual é especialista e do conhecimento para 


\section{CULTURA ORGANIZACIONAL DE UMA UNIVERSIDADE BRASILEIRA: UMA ANÁLISE DOS \\ VALORES E PRÁTICAS ORGANIZACIONAIS NA PERCEPÇÃO DOS DOCENTES \\ DOI: https://doi.org/10.5007/1983-4535.2021.e75461}

realização de pesquisas, chegando a aspectos mais abrangentes, que revelam a importância da formação pedagógica dos docentes. Canan e Santos (2019) corroboram a percepção de que os docentes do ensino superior necessitam de elementos que excedem os conhecimentos específicos e incluem a boa comunicação, aulas conjuntas com os estudantes, com participação dos mesmos, bom relacionamento com as turmas e conhecimentos didáticopedagógicos para propiciar novas metodologias de ensino.

Por fim, o terceiro fator de práticas organizacionais analisado é a "promoção do relacionamento interpessoal", o qual associa-se às práticas que visam fortalecer a coesão interna por meio da promoção das relações interpessoais e satisfação dos funcionários (FERREIRA; ASSMAR, 2008). As médias, desvio padrão e classificação dos itens relacionados a promoção do relacionamento interpessoal estão contidos na Tabela 6 .

Tabela 6 Média, desvio padrão e classificação dos itens do fator promoção do relacionamento interpessoal

\begin{tabular}{|c|c|c|c|}
\hline Itens & Média & Desvio Padrão & Classificação \\
\hline Os docentes têm ampla liberdade de acesso aos diretores. & 4,25 & 0,883 & \multirow[b]{2}{*}{ ALTO } \\
\hline $\begin{array}{l}\text { As relações entre docentes e membros do alto escalão são } \\
\text { cordiais e amigáveis. }\end{array}$ & 3,78 & 0,972 & \\
\hline Os docentes se relacionam como se fossem uma grande família. & 2,185 & 1,066 & \\
\hline É prática comum a comemoração dos aniversários pelos docentes. & 2,21 & 1,154 & MODERADO \\
\hline PROMOÇÃO DO RELACIONAMENTO INTERPESSOAL & 60,131 & 16,042 & \\
\hline
\end{tabular}

Fonte: Dados da pesquisa (2019).

A partir das análises apresentadas na Tabela 6 , verifica-se que os itens se referem à relação entre docentes e superiores sob um aspecto profissional os quais apresentam-se com resultados positivos. Os itens que apresentaram médias mais baixas, entre 2,1 e 2,2, dizem respeito a relações mais próximas entre os docentes, apontando que os mesmos percebem que esses aspectos não são tão aplicados em seu meio laboral. Na padronização das escalas, a classificação o fator "promoção do relacionamento interpessoal" concentra-se entre moderado $(56,5 \%)$ a alto $(38,5 \%)$.

Nas análises qualitativas sobre este fator, quatro docentes relataram aspectos positivos e alguns pontos neutros no tocante às relações interpessoais; outros três mencionam aspectos positivos e negativos e apenas um relata uma percepção negativa em relação à promoção do relacionamento interpessoal, como pode ser observado nas falas de alguns dos entrevistados: 
Com a direção como fui chefe de departamento eu diria que é ótima assim, em todas as vezes que eu precisei ali eu recebi apoio, enfim né e mesmo não sendo mais chefe de departamento, como professor idem [...] (BR3).

Com alguns é muito boa, com alguns é boa e com outras poderia ser melhor do que eu gostaria né, é [...] eu procuro assim no meu perfil, eu tento ser um aglutinador assim de não separar as pessoas [...] eu não vou te dizer que eu me relaciono bem com todos porque não tenho essa proximidade com todos, [...] (BR6).

Com base nas falas dos docentes, a maioria menciona ter um bom relacionamento com seus colegas, diretores e outros superiores, ainda que seja ressaltado a falta de proximidade entre os docentes. Tal resultado é um ponto que merece atenção já que, de acordo com Silva e Simões (2015), as organizações assumem importância como locais para estabelecimento de relacionamentos interpessoais devido a socialização existente entre as pessoas promovendo sentido as relações.

\section{CONSIDERAÇÕES FINAIS}

Com base na percepção dos docentes participantes, este estudo teve como objetivo identificar a cultura organizacional de uma universidade brasileira. A partir dos dados quantitativos e qualitativos encontrados, organizados por meio dos fatores investigados. Os itens dos fatores da Cultura Organizacional avaliados por meio do IBACO receberam classificações de moderado a alto, com exceção do fator treinamento e recompensas, que teve itens que apresentaram a classificação moderada, mas outros como baixa. Com isso, a ordem dos fatores mais bem avaliados a partir dos dados quantitativos para essa amostra é: integração externa, profissionalismo cooperativo, promoção do relacionamento interpessoal, satisfação e bem-estar dos empregados, profissionalismo competitivo, recompensa e treinamento.

Quanto aos fatores de valores da Cultura Organizacional, o primeiro analisado foi o profissionalismo cooperativo. As análises quantitativas para esse fator apontaram uma classificação entre moderado a superior. Nos dados qualitativos, a análise dos docentes foi positiva quanto a existência de cooperação no meio laboral. No entanto, quando investigado sobre a percepção dos docentes em relação a valorização da cooperação, identificou-se que apenas um docente brasileiro percebe que, de alguma maneira, há certa valorização da cooperação no meio universitário. 


\section{CULTURA ORGANIZACIONAL DE UMA UNIVERSIDADE BRASILEIRA: UMA ANÁLISE DOS \\ VALORES E PRÁTICAS ORGANIZACIONAIS NA PERCEPÇÃO DOS DOCENTES \\ DOI: https://doi.org/10.5007/1983-4535.2021.e75461}

O profissionalismo competitivo classificou-se como moderado na percepção dos docentes a partir da análise dos dados quantitativos. Ao analisar esse fator qualitativamente, os docentes brasileiros apontam associações entre a competitividade e as atividades relacionadas à pesquisa. Em relação ao último fator de valor, que se refere a satisfação e bemestar dos empregados, a classificação quanto a percepção dos docentes deu-se majoritariamente como moderada. Nas análises qualitativas houve percepções distintas entre os docentes, que não pareceram ter um consenso sobre este aspecto. Porém, a maior parte dos docentes aponta que há essa preocupação por parte da instituição, mas é necessária maior divulgação dessas ações.

Em relação aos fatores de práticas, o primeiro diz respeito à integração externa, que obteve classificação como alto, sendo o mais bem avaliado pelos docentes. Nas análises qualitativas, evidenciou-se que há uma boa relação com os discentes, ainda que possam existir alguns conflitos em determinados momentos. Além disso, citam a preocupação com a capacitação como meio de alcançar os objetivos da docência, em que dão ênfase à necessidade de reconhecer e considerar a heterogeneidade da turma no processo de aprendizagem.

No que tange às práticas de recompensa e treinamento, os docentes classificaram essa dimensão como de moderada a baixa, sendo o fator com pior avaliação. Na análise dos dados qualitativos houve certa discrepância entre as informações, já que foram relatados aspectos positivos e negativos. No entanto, de um modo geral, evidencia-se a necessidade das instituições esclarecerem as políticas relacionadas a recompensas, visto que podem propiciar maior senso de valorização aos docentes. Quanto as práticas de treinamentos, os docentes de apontaram percepções positivas a respeito desse fator, ainda que apontassem possibilidades de melhorias. Salienta-se a necessidade de maior adesão aos programas de treinamento, especialmente pelos docentes perceberem o investimento da instituição nesse aspecto.

Por fim, a dimensão promoção do relacionamento interpessoal apresentou-se como de moderada a alta para os docentes, que foi confirmada pelos dados qualitativos, já que a maior parte dos docentes apresentaram considerações positivas quanto a esse fator. No entanto, também houve falas negativas, em que o distanciamento entre os colegas de trabalho foi mencionado, evidenciando ser um ponto que a universidade pode pensar em estratégias para favorecer as relações interpessoais no trabalho. 
Dentre as contribuições da pesquisa evidencia-se a possibilidade elaboração de estratégias para modificação gradual da cultura organizacional visando fortalecer a adesão de docentes aos treinamentos, melhorar as relações interpessoais no trabalho e implementar ações que visem o bem-estar dos docentes, a fim de proporcionar um local de trabalho com uma cultura que favoreça ainda mais o desenvolvimento das atividades dos docentes. Como limitações do estudo é importante citar o número reduzido da amostra de participantes, o que dificulta a análise da percepção dos docentes em sua totalidade, especialmente por contemplares diferentes áreas do conhecimento.

\section{REFERÊNCIAS}

AMARAL, G. A.; BORGES, A. L.; JUIZ A. P. M. Organização do trabalho, prazer e sofrimento de docentes públicos federais. Cadernos de Psicologia Social do Trabalho, 20 (1), 15-28, 2017.

BARDIN, L. Análise de conteúdo. São Paulo: Edições 70, 2016.

BARALE, R. F.; SANTOS, B. R. Cultura organizacional: Revisão sistemática da literatura. Revista Psicologia: Organizações e Trabalho, 17 (2), 129-136, 2017.

BARBIERI, U. F. Gestão de pessoas nas organizações: conceitos básicos e aplicações. São Paulo: Atlas, 2016.

BARBOSA, L. Cultura e empresas. Rio de Janeiro: Zahar, 2002.

BENDASOLLI, P. F. Work and culture: Approaching cultural and work psychology. Culture \& Psychology, 23 (3), 372-390, 2016.

BOSI, A. P. A precarização do trabalho docente nas instituições de ensino superior do brasil nesses últimos 25 anos. Educação \& sociedade. 28 (101), 1503-1523, 2007.

CANAN, S. R. \& SANTOS, C. F. S. Educação superior em tempos de crise: há espaço nas políticas de educação para a discussão do professor universitário? EccoS Revista Cientifica, 48, 339-36, 2019.

COSTA, S. G. Comportamento organizacional: cultura e casos brasileiros. Rio de Janeiro: LTC, 2014.

DIAS, R. Cultura organizacional: construção, consolidação e mudanças. São Paulo: Atlas, 2013.

FLEURY, M. T. L. Estórias, mitos, heróis: cultura organizacional e relações do trabalho.

Revista de Administração de Empresas, 27 (4),7-18, 1987. 
FLEURY, M. T. L. Aprendendo a mudar - aprendendo a aprender. Revista de Administração. 30 (3), 5-11, 1995.

FERREIRA, M. C.; ASSMAR, E. M. L.; ESTOL, K. M. F.; HELENA, M. C. C. C.; CISNE, M. C. F. Desenvolvimento de um instrumento brasileiro para avaliação da cultura organizacional. Estudos de Psicologia, 7 (2), 271-280, 2002.

FERREIRA, M. C.; ASSMAR, E. M. L. Cultura Organizacional. In: SIQUEIRA, M. M. M. et al. (Orgs). Medidas do Comportamento Organizacional: ferramentas de diagnóstico e de gestão. São Paulo: Artmed, 2008.

HAIR, JR. J. F.; BLACK, W.C.; ANDERSON, R. E.; TATHAN, R. L. Análise multivariada de dados. Porto Alegre: Bookman, 2009.

JUST, M. D.; BATISTELLA, C.; TAUFFER, E.; MACKE, J. A. Cultura Organizacional em uma Instituição de Ensino Superior Privado, na Perspectiva de Diferentes

Públicos. Contextus - Revista Contemporânea de Economia e Gestão, 16 (1), 8-31, 2018.

LEMOS, D. Trabalho docente nas universidades federais: tensões e contradições. Caderno CRH, 24 (1),105-120, 2011.

LOPES, L. F. D. Métodos Quantitativos Aplicados ao Comportamento Organizacional. Santa Maria: Voix, 266, 2018.

LORENTZIADIS, R. A. B. Cooperação Organizacional: Sua importância e promoção sob os aspectos da motivação e da personalidade. 2002. Dissertação de Mestrado, Administração de Empresas, Escola Brasileira de Administração Pública, Empresas da Fundação Getúlio Vargas, São Paulo, 2002.

MARQUESE, E. C.; MORENO, C. R. C. Satisfação no trabalho - uma breve revisão. Revista Brasileira de Saúde Ocupacional. 30 (112), 69-79, 2005.

PACHANE, G. G.; PEREIRA, E. M. A. Em relação à formação pedagógico-pedagógica e construção de um novo perfil para professores universitários. Revista Ibero-americana de Educação, 35 (1), 1-13, 2004.

PATRUS, R.; DANTAS, D. C.; SHIGAKE, H. B.O produtivismo acadêmico e seus impactos na pós-graduação stricto sensu: uma ameaça à solidariedade entre pares? Cadernos

EBAPE.BR, 13 (1), 2015.

PEREZ, F. C.; COBRA, M. Cultura organizacional e gestão estratégica: a cultura como recurso estratégico. São Paulo: Atlas, 2017.

PÉREZ, J. T.; RODRÍGUEZ, J. F. G. La cultura organizacional y la satisfacción laboral en la delegación federal de la secretaría de educación pública (sep) en el estado de tabasco. Hitos De Ciencias Economico Administrativas, 22 (64), 184-202, 2016. 
SILVA, M. P., SIMÕES, J. M. O estudo do sentido do trabalho: contribuições e desafios para as organizações contemporâneas. Revista Capital Científico - Eletrônica (RCCe), 13 (3), 2015.

SCHEIN, E. H. Coming to a new awareness of organizational culture. Sloan Management Review. Massachusetts Institute of Technology, 25 (2), 3-16, 1984.

SCHEIN, E. H. Cultura organizacional e liderança. São Paulo: Atlas, 2009. 